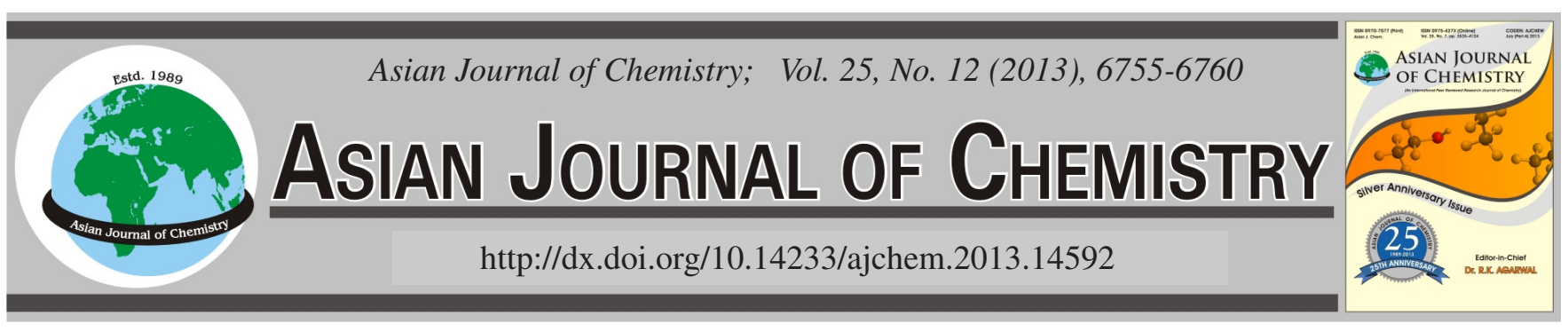

\title{
Compositional Analysis and Antioxidant Activity Assessment of Polysaccharide Extracted from Snow Lotus (Saussurea) Species
}

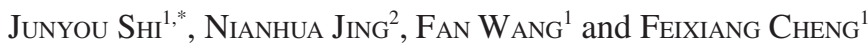

${ }^{1}$ College of Chemistry Science, Qujing Normal University, Qujing, P.R. China

${ }^{2}$ College of Biological resources and Environmental Sciences, Qujing Normal University, Qujing, P.R. China

*Corresponding author: Tel./Fax: +86 874 8998658; E-mail: shijunyou123@126.com

(Received: 17 September 2012;

Accepted: 31 May 2013)

AJC-13565

\begin{abstract}
Plant polysaccharides have been paid more attentions due to their effects on normal health and chronic diseases. A selective and sensitive method based on pre-column derivatization using 1-(2-naphthyl)-3-methyl-pyrazolone as the labeling reagent followed by high performance liquid chromatography with ultraviolet detection and online mass spectrometry identification (HPLC/DAD-ESI/MS) has been developed. Each monosaccharide was derivatized by 1-(2-naphthyl)-3-methyl-pyrazolone and separated on an Akasil-C18 column. Nine monosaccharides investigated presented excellent linear responses $\left(r^{2}>0.9993\right)$. Limits of detection and quantification varied from 0.33 to 2.06 pmol and 1.10 to $6.82 \mathrm{pmol}$, respectively. Compositional analysis of polysaccharides from Saussurea involucrata, S. laniceps and $S$. medusa was made by this method. Galacturonic acid, rhamnose, glucose + galactose and arabinose were found to be the major components. Additionally, antioxidant activities of polysaccharides from these three species were comparatively assessed. Polysaccharides from $S$. involucrate and $S$. laniceps showed similar antioxidant activities, which relatively higher than that of $S$. medusa.
\end{abstract}

Key Words: Monosaccharide, Saussurea, HPLC/DAD-ESI/MS, Pre-column derivatization, Antioxidant activity.

\section{INTRODUCTION}

Snow lotus herb is a collection of 40 species of geneus Saussurea ${ }^{1}$. This herb, grows in the mountains at heights about $2100-4100 \mathrm{~m}^{2}$, is frequently used as ethnomedicinal drug of Tibet $^{3}$, Mongolia ${ }^{4}$ and Uygur ${ }^{5}$. Modern pharmacological researches demonstrate that snow lotus has analgesic ${ }^{6,7}$, anticancer $^{8,9}$, resist early-foetation ${ }^{10,11}$ and free radical scavenging effects $^{12,13}$. Pharmacological effects are closely related to chemical components. A series of active components which could provide beneficial therapeutic effects including phenolic compounds $^{14}$, sesquiterpenes ${ }^{15}$, lignins ${ }^{16}$ and polysaccharide ${ }^{17}$ have been isolated from snow lotus.

Currently, three snow lotus species including S. involucrata, S. laniceps and S. medusa are all used as an herbal drug for the treatment of inflammation and pain-related diseases which might limit their further bioactive screening and clinical popularization $^{8}$. To solve this problem, several attempts ${ }^{5,18}$ have been done to assess the qualitative and quantitative difference in these three related herbs using HPLC/DAD-MS and UPLC. In these studies, phenolic compounds including phenolic acids, flavonoids and lignans have been compared systemically, which gave an important clue to the quality control and use of $S$. involucrata, S. laniceps and S. medusa. However, one important ingredient in these snow lotus species named polysaccharide was neglected in the above studies.

Today, polysaccharides from plants, which are almost innocuous $^{19}$, have been paid more and more attentions due to their effects on normal health and chronic diseases, such as enhancement of immune function ${ }^{20}$, reduction of blood sugar ${ }^{21}$, activities on antitumor ${ }^{22}$, antivirus ${ }^{23}$ and antiaging ${ }^{24}$. According to Fang and Ye's research ${ }^{10}$, polysaccharide from snow lotus could terminate pregnancy by stimulating uterus at every stage of sexual activity. Additionally, free radical scavenging effect and antifatigue function of polysaccharide from snow lotus have been reported ${ }^{13}$. Herein, compositional investigation of polysaccharide is equally essential to pharmacological research of snow lotus.

Monosaccharides have a number of isomers and homologs that structurally resemble one another. This problem makes it a great challenge for conventional methods to separate these isomers ${ }^{25}$. Owing to absence of specific chromosphores or fluorophores, analysis of monosaccharides with ultraviolet detection is invalid ${ }^{26}$. Refractive index detectors used for the analysis also have limitations, e.g. low sensitivity and incompatibility with gradient elution ${ }^{25}$. To solve this problem, Honda et al. ${ }^{27}$ presented a new derivatization method with 1-phenyl3-methyl-5-pyrazolone (PMP) as the labeling reagent. In this 
condensation reaction, active carbon $(\mathrm{C}-4)$ in monosaccharide molecular chain reacted with the aldehyde function group in 1-phenyl-3-methyl-5-pyrazolone under a mild condition. Up to date, this derivatization method has been continuously developed. In the present work, a selective and sensitive HPLC/ DAD-ESI/MS method using 1-(2-naphthyl)-3-methylpyrazolone (NMP) as the labeling reagent was developed to give a comparable compositional analysis of polysaccharide from $S$. involucrata, $S$. laniceps and $S$. medusa. At the same time, antioxidant activities of polysaccharide extracted from these snow lotuses were estimated to improve the present day knowledge of S. involucrata, S. laniceps and S. medusa.

\section{EXPERIMENTAL}

HPLC analysis was performed on Agilent HP 1100 series high performance liquid chromatography. This apparatus equipped with an online vacuum degasser (model G1322A), a quaternary pump (model G1311A), an autosampler (model G1329A), a thermostated column compartment (model G1316A) and a diode array detector (DAD) (model G1315A). At the same time, Aglient 1100 series LC-MSD Trap-SL (ion trap) mass spectrometer from Bruker Daltonik (Bremen, Germany) equipped with electrospray ionization (ESI) ion source was used for the post-column identification.

Standards of nine monosaccharides including mannose, galacturonic acid, glucuronic acid, rhamnose, glucose, galactose, arabinose, xylose and fucose were purchased from Sigma Reagent Co. (St. Louis, MO, USA). HPLC-grade acetonitrile was obtained from Yuwang Chemical Reagent Co. (Shandong Province, China).Water was purified on a Milli-Q system (Millipore, Bedford, MA, USA). All other reagents used were of analytical grade unless otherwise stated. 1-(2-Naphthyl)3-methyl-pyrazolone was synthesized according to You's method $^{28}$.

Preparation of standards and samples: Standard solution $\left(0.01 \mathrm{~mol} \mathrm{~L}^{-1}\right)$ was prepared by dissolving nine monosaccharide standards in $10 \mathrm{~mL}$ deionized water. Reagent solution $(0.05$ mol L ${ }^{-1}$ ) was prepared by dissolving $112 \mathrm{mg}$ 1-(2-naphthyl)3-methyl-pyrazolone in $10 \mathrm{~mL}$ acetonitrile. S. involucrata was collected from Urumqi in Xinjiang Uighur Autonomous Region of China. S. laniceps was obtained from Cuona in Tibet of China and S. medusa was from Qilian in Qinghai Province of China. Taxonomic identification followed the study of Yi et al. ${ }^{8}$ and representative voucher specimens were deposited at the herbarium of Northwest Institute of Plateau Biology, Chinese Academy of Sciences. Crude polysaccharide from each snow lotus species was extracted as follows: $10 \mathrm{~g}$ dried power was refluxed with $150 \mathrm{~mL}$ of petroleum ether at $65^{\circ} \mathrm{C}$ for $2 \mathrm{~h}$ to remove lipids $(n=2)$. Subsequently, the residue was refluxed twice with $150 \mathrm{~mL} \mathrm{H}_{2} \mathrm{O}$ at $95^{\circ} \mathrm{C}$ for $3 \mathrm{~h}$. The extract was then deproteinated (Seavge method) after reduced concentration at $60{ }^{\circ} \mathrm{C}$. After that, a four-fold volume of ethanol was added to precipitate the polysaccharide obtained by centrifugation. Crude polysaccharide ( $10 \mathrm{mg}$ ) was then placed in $2 \mathrm{~mL}$ vial; $2 \mathrm{~mol} \mathrm{~L}^{-1}$ trifluoroacetic acid (TFA, $1 \mathrm{~mL}$ ) was added and the vial was sealed. After hydrolysis at $110^{\circ} \mathrm{C}$ for $2 \mathrm{~h}$, the contents were adjusted to $\mathrm{pH} 7$ with $2 \mathrm{~mol} \mathrm{~L}^{-1} \mathrm{NaOH}$ and filtered through a $0.2 \mathrm{~mm}$ nylon membrane filter.
Derivatization procedures: $20 \mu \mathrm{L}$ monosaccharide standard solution, $200 \mu \mathrm{L}$ 1-(2-naphthyl)-3-methyl-pyrazolone solution and $20 \mu \mathrm{L}$ ammonia water $(17 \%)$ were consecutively added in a $2 \mathrm{~mL}$ vial. The vial was sealed and allowed to react in a water-bath for $35 \mathrm{~min}$ at $70^{\circ} \mathrm{C}$. After derivatization, the mixture was dried under a nitrogen stream. Then the residue was redissolved in $1 \mathrm{~mL}$ solution of acetonitrile-water (4:1, v/v) and then was injected directly for analysis. Derivatization for the samples was similar as described above. Scheme of 1-(2naphthyl)-3-methyl-pyrazolone with monosaccharide was shown in Fig. 1.

HPLC separation and MS conditions: HPLC separation of nine monosaccharides was performed on a reversed-phase Akasil C18 column $(250 \times 4.6 \mathrm{~mm}$ i.d, $5 \mu \mathrm{m})$ with a gradient elution. Eluent A was $100 \% \mathrm{H}_{2} \mathrm{O}$ containing $30 \mathrm{mM}$ ammonium acetate buffer $(\mathrm{pH}=4)$; B was $100 \%$ acetonitrile. Elution conditions were: (1) 0-10 min, A: $90 \%$, B: $10 \%$; (2) 10-20 min, A: $90-84 \%$, B: $10-16 \%$; (3) 20-40 min, A: $84-50 \%$, B: $16-50 \%$. Flow rate was constant at $1 \mathrm{~mL} \mathrm{~min}^{-1}$. Column temperature was kept at $25^{\circ} \mathrm{C}$. DAD detection wavelength was set at $254 \mathrm{~nm}$. ESI source was evaluated for identification of monosaccharide derivatives. ESI conditions: spray pressure, 35 p.s.i (1 p.s.i = 6894.76 Pa); dry gas temperature, $350{ }^{\circ} \mathrm{C}$; dry gas flow, $9.0 \mathrm{~L} \mathrm{~min}^{-1}$; capillary voltage, $3500 \mathrm{~V}$. Positiveion detection mode was selected.

Assessment of antioxidant activity: ABTS assay was based on the method of Re et al. ${ }^{29}$ with modification. ABTS ${ }^{\bullet+}$ reagent was produced by reacting $10 \mathrm{~mL}$ of $7 \mathrm{mM}$ ABTS solution with $178 \mu \mathrm{L}$ of $140 \mathrm{mM}$ potassium persulfate aqueous in the dark at room temperature for $15 \mathrm{~h}$ before use. The $\mathrm{ABTS}^{\bullet+}$ solution was diluted to appropriate absorbance. $1 \mathrm{~mL}$ of different concentration sample $\left(25-500 \mu \mathrm{g} \mathrm{mL}^{-1}\right), 2 \mathrm{~mL}$ of diluted $\mathrm{ABTS}^{\bullet+}$ solution and $1 \mathrm{~mL}$ of $\mathrm{H}_{2} \mathrm{O}$ were consecutively added to react in the dark at room temperature for $0.5 \mathrm{~h}$ and the absorbance at $734 \mathrm{~nm}$ was recorded. All the samples were tested three times.

Reducing power was determined according to the method of Wang et $a l .^{30}$. Briefly, $1.5 \mathrm{~mL}$ of different concentration sample $\left(25-500 \mu \mathrm{g} \mathrm{mL}^{-1}\right)$ was mixed with $0.5 \mathrm{~mL}$ of phosphate buffer ( $\mathrm{pH} 6.6$ ) and $0.5 \mathrm{~mL}$ of $1 \%(\mathrm{w} / \mathrm{v})$ potassium ferricyanide solution. The mixture was incubated in a water bath at $50{ }^{\circ} \mathrm{C}$ for $20 \mathrm{~min}$. Afterward, $1 \mathrm{~mL}$ of $10 \%$ (w/v) trichloroacetic acid solution was added, and the mixture was then centrifuged at $800 \mathrm{rpm}$ for $10 \mathrm{~min}$. A $3 \mathrm{~mL}$ aliquot of the upper layer was then combined with $0.5 \mathrm{~mL}$ of $0.1 \%$ (w/v) ferric chloride solution, and the absorbance was measured at $700 \mathrm{~nm}$. All the samples were tested three times.

\section{RESULTS AND DISCUSSION}

Optimum chromatography: Several factors influencing the chromatographic separation were investigated. These factors included columns, gradient elution conditions and $\mathrm{pH}$ value of the mobile phases. Various columns including Hypersil C18 (200 mm × $4.6 \mathrm{~mm}, 5 \mu \mathrm{m})$, Hypersil BDS C18 $(200 \mathrm{~mm}$ $\times 4.6 \mathrm{~mm}, 5 \mu \mathrm{m})$, Spherisorb C18 $(200 \mathrm{~mm} \times 4.6 \mathrm{~mm}, 5 \mu \mathrm{m})$ and Hypersil BDS C8 $(200 \mathrm{~mm} \times 4.6 \mathrm{~mm}, 5 \mu \mathrm{m})$ were evaluated. These short columns resulted in low resolution. Some researchers have reported that long columns were helpful to 
<smiles>CC1=NN(c2ccc3ccccc3c2)C(=O)C1</smiles>

NMP<smiles>CC1=NN(c2ccc3ccccc3c2)C(=O)C1</smiles>

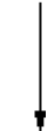

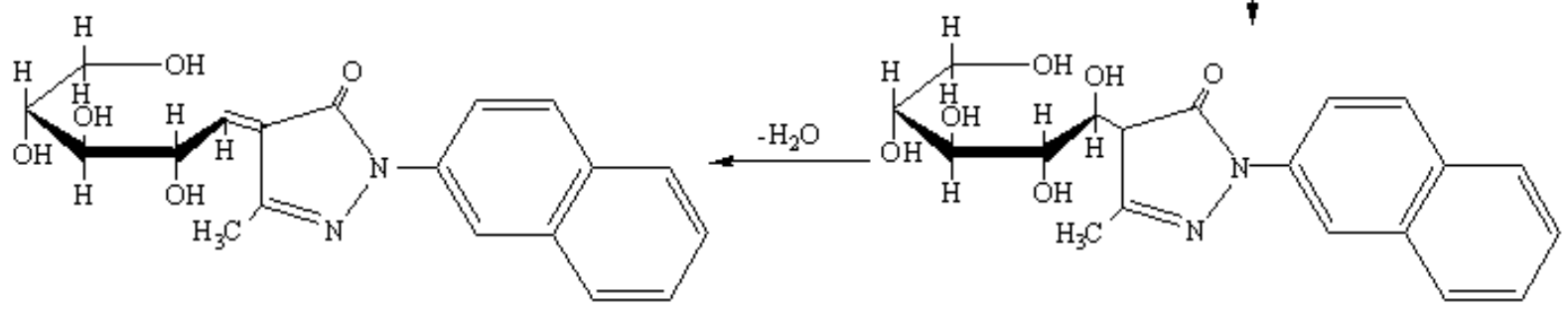

$+$<smiles>CC1=NN(c2ccc3ccccc3c2)C(=O)C1</smiles><smiles>CC1=NN(c2ccc3ccccc3c2)C(=O)C1C(C)(C)C[C@H](O)[C@H](O)CO</smiles>

NMP-xylose derivative

Fig. 1. Derivatization scheme of 1-(2-naphthyl)-3-methyl-pyrazolone (NMP) with representative xylose

the separation of analysis ${ }^{31}$. Thus, we use the column Akasil C18 $(250 \times 4.6 \mathrm{~mm}$ i.d, $5 \mu \mathrm{m})$ with satisfactory chromatographic resolution.

Due to the presence of hydroxyl and carboxylic groups, polarity of monosaccharide compounds was much high. Although polarity of these compounds was lower after derivatization, it was also relatively higher than other chemicals, e.g. fatty acids. Thus, when considering the gradient elution conditions, proportion of mobile phase $\mathrm{A}\left(100 \% \mathrm{H}_{2} \mathrm{O}\right)$ were relatively higher. At the same time, gradient elution conditions selected were mild because of the existion of several pairs of isomers.

The $\mathrm{pH}$ value of mobile phases could significantly affect the resolution because of the presence of several hydroxyl groups. In addition, due to the fact that molecules of galacturonic acid and glucuronic acid contained one carboxylic group, respectively, the acidic mobile phase was selected. To achieve optimal mass spectra sensitivity, ammonium acetate buffer $(\mathrm{pH}$ =4) with different concentrations $(10,15,20,25,30 \mathrm{mM})$ were chosen. Retention times of each analyte would remove backwards when the $\mathrm{pH}$ value of mobile phases became low. In the present, $30 \mathrm{mM}$ ammonium acetate buffer was selected.

Derivatization interference was an important factor which would influence the accuracy of analysis. Samples of derivatization blank prepared by replacing monosaccharide standard with deionized water were injected. Results obtained (Fig. 2b) indicated that there was no detectable signal from blank deionized water samples.
These conditions could achieve a complete baseline resolution for monosaccharide derivatives within the shortest time with the exception of 1-(2-naphthyl)-3-methyl-pyrazoloneglucose and 1-(2-naphthyl)-3-methyl-pyrazolone-galactose being co-eluted (Fig. 2a). Further experiments including decrease of column temperature and alteration of gradient were not successful. Similar results were observed in other literatures ${ }^{32,33}$.

MS characterization of monosaccharide-1-(2-naphthyl)-3-methyl-pyrazolone derivatives: Each derivative investigated presented an intense molecular ion peak at $\mathrm{m} / \mathrm{z}$ $[\mathrm{M}+\mathrm{H}]^{+}$and corresponding characteristic fragment ions (Table1, Fig. 3). These characteristic fragment ions were listed as follows: (1) $\left[\mathrm{M}+\mathrm{H}-\mathrm{H}_{2} \mathrm{O}\right]^{+}$, this fragment was produced by losing one $\mathrm{H}_{2} \mathrm{O}$ molecule from the molecular ion $[\mathrm{M}+\mathrm{H}]^{+}$; (2) $[\mathrm{M}+\mathrm{H}-\mathrm{NMP}]^{+}$, this fragment was from the molecular ion $[\mathrm{M}+\mathrm{H}]^{+}$by losing one 1-(2-naphthyl)-3-methyl-pyrazolone; (3) $[\mathrm{NMP}+\mathrm{H}]^{+}$, namely the ion of 1-(2-naphthyl)-3-methylpyrazolone released from the monosaccharide derivative; (4) the fragment ion from cleavage of $\mathrm{C} 2-\mathrm{C} 3$ bond in the monosaccharide chain of the corresponding derivative; due to the difference of structure, this ion for neutral monosaccharide derivative could be presented as $\left[\mathrm{M}+\mathrm{H}-\mathrm{C}_{\mathrm{m}} \mathrm{H}_{2 \mathrm{~m}+1} \mathrm{O}_{\mathrm{m}}-\mathrm{H}_{2} \mathrm{O}\right]^{+},(\mathrm{m}=\mathrm{n}-2$, $\mathrm{n}$ represented the number of carbon atoms in the monosaccharide molecule); when considering uronic acid, this expression should be adjust to $\left[\mathrm{M}+\mathrm{H}-\mathrm{C}_{\mathrm{m}} \mathrm{H}_{2 \mathrm{~m}-1} \mathrm{O}_{\mathrm{m}+1}-\mathrm{H}_{2} \mathrm{O}\right]^{+}$; as for deoxymonosaccharide derivative, the ion mentioned above should be expressed in terms of $\left[\mathrm{M}+\mathrm{H}-\mathrm{C}_{\mathrm{m}} \mathrm{H}_{2 \mathrm{~m}+1} \mathrm{O}_{\mathrm{m}-1}-\mathrm{H}_{2} \mathrm{O}\right]^{+}$. Cleavage mode of the representative xylose was shown in Fig. 4. 

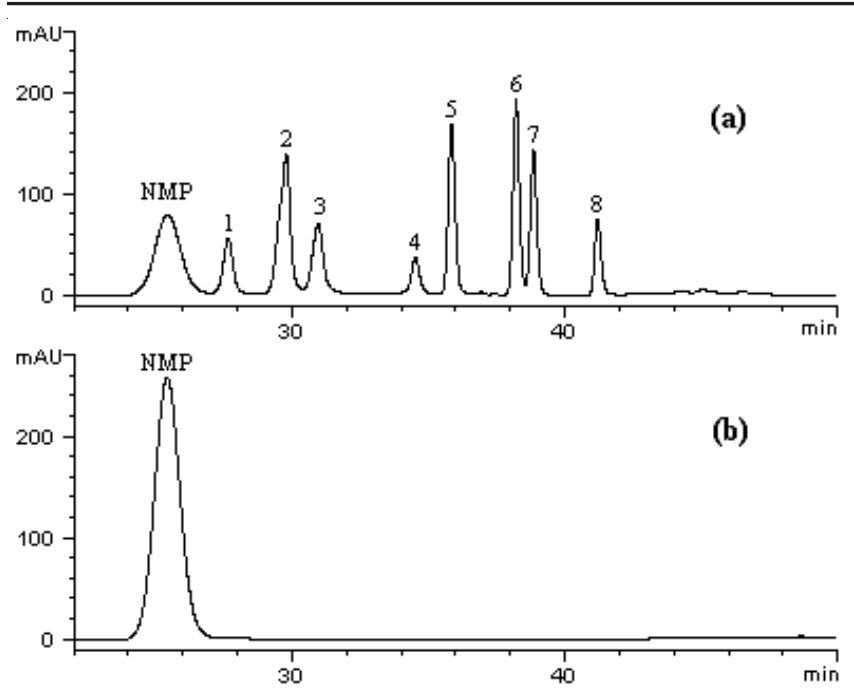

\begin{tabular}{lccc}
\multicolumn{4}{c}{ TABLE-1 } \\
\multicolumn{4}{c}{ MASS DATA OF THE MONOSACCHARIDE DERIVATIVES } \\
\hline $\begin{array}{c}\text { NMP- } \\
\text { monosaccharide } \\
\text { derivative }\end{array}$ & $\begin{array}{c}\text { Molecular } \\
\text { ion }[\mathrm{M}+\mathrm{H}]^{+}\end{array}$ & $\begin{array}{c}{[\mathrm{M}+\mathrm{H}-} \\
\left.\mathrm{H}_{2} \mathrm{O}\right]^{+}\end{array}$ & MS/MS \\
\hline $\begin{array}{l}\text { Mannose } \\
\text { Galacturonic acid }\end{array}$ & 611.4 & 592.7 & $387.0,225.2,473.4$ \\
$\begin{array}{l}\text { Glucuronic acid } \\
\text { Rhamnose }\end{array}$ & 625.3 & 607.2 & $400.9,225.1,473.2$ \\
Glucose + & 595.3 & 607.2 & $401.0,225.1,473.3$ \\
Galactose & 611.4 & 577.3 & $371.0,225.1,473.3$ \\
Arabinose & 593.2 & $386.6,225.0,473.2$ \\
Xylose & 581.3 & 563.5 & $356.8,225.0,473.2$ \\
Fucose & 581.3 & 563.0 & $356.7,225.1,472.8$ \\
\hline & 595.3 & 577.4 & $371.2,225.0,473.2$ \\
\hline
\end{tabular}

Validation of the HPLC-DAD method: Calibration curves (Table-2) were established using the regression of the peak area versus concentration of each monosaccharide standard $(n=3)$. Concentrations ranged from 7.81 to 2000 pmol. Each monosaccharide derivative showed excellent linear response with coefficient $=0.9993$ (Table-2) . Limits of detection (LOD) were determined based on a signal-to-noise ratio
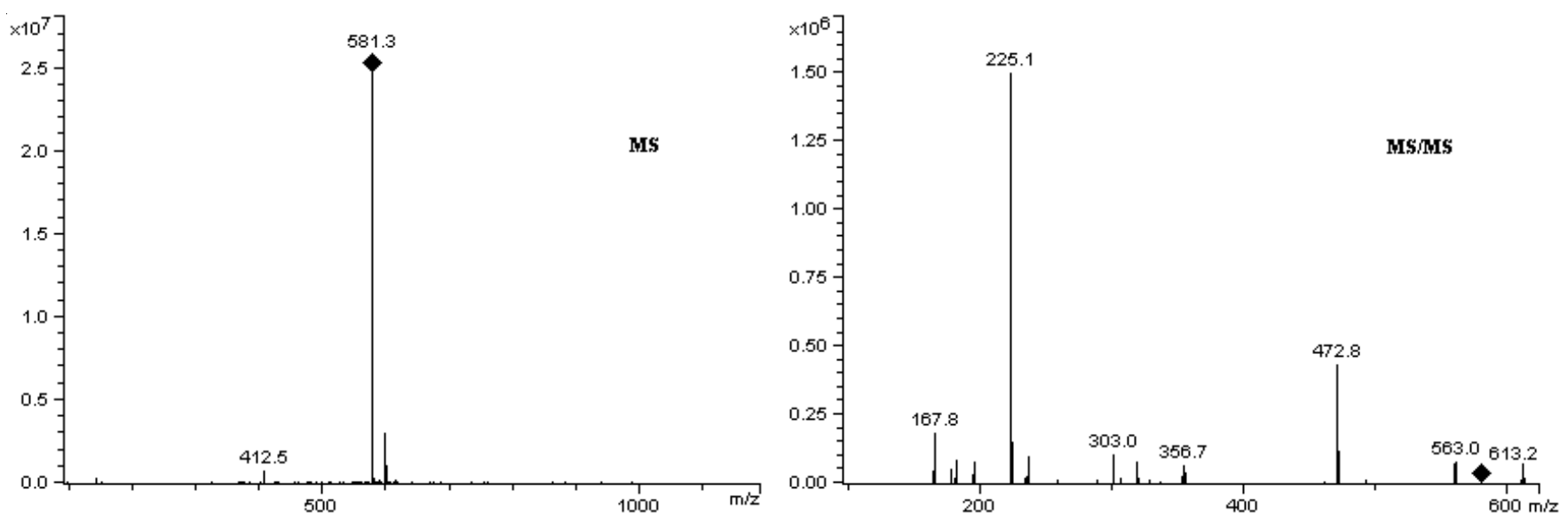

Fig. 3. Mass spectra for the representative xylose

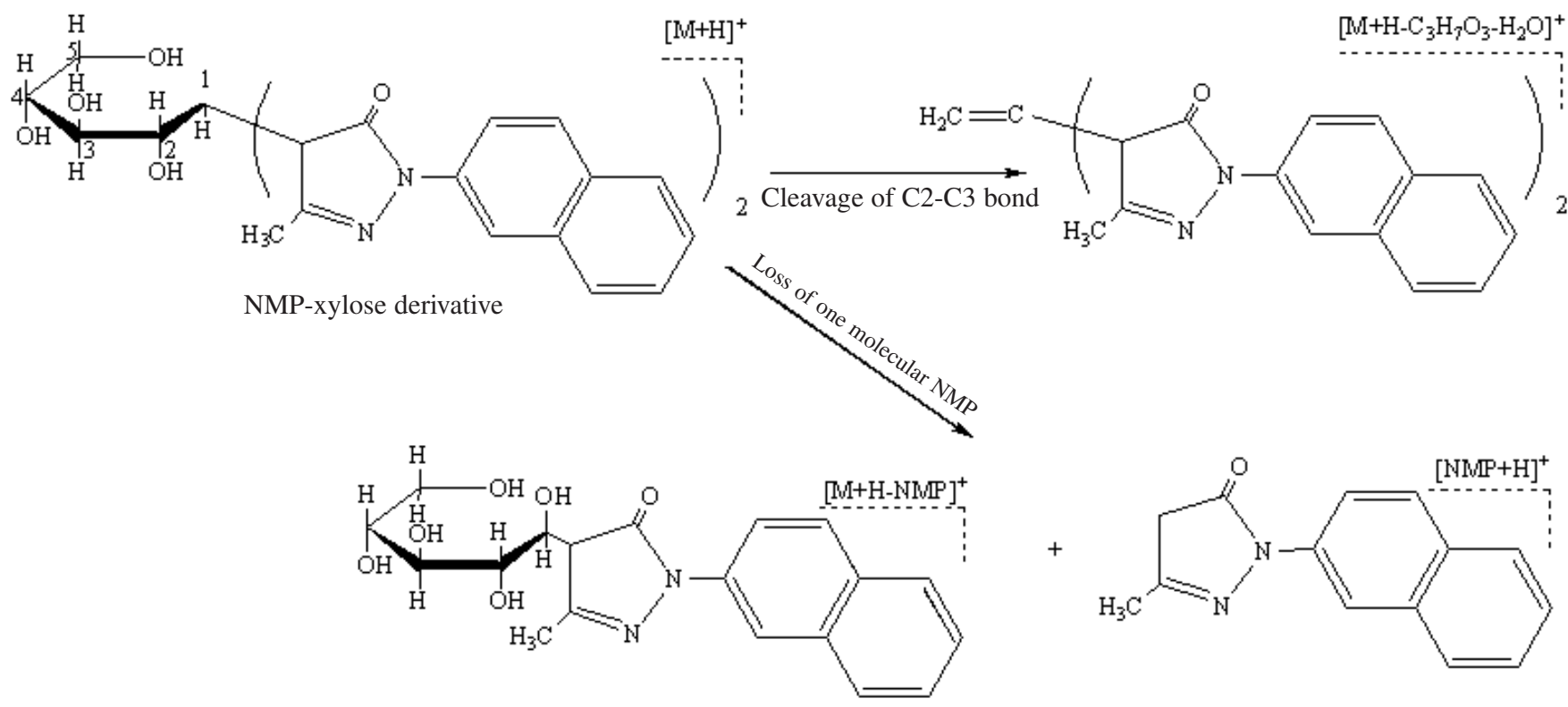

Fig. 4. Cleavage mode for the representative xylose 


\begin{tabular}{|c|c|c|c|c|}
\hline \multicolumn{5}{|c|}{$\begin{array}{c}\text { TABLE-2 } \\
\text { LINEAR REGRESSION EQUATIONS, CORRELATION COEFFICIENTS, LIMIT OF } \\
\text { DETECTION (LOD) AND LIMIT OF QUANTIFICATION (LOQ) }\end{array}$} \\
\hline $\begin{array}{c}\text { NMP-monosaccharide } \\
\text { derivative }\end{array}$ & $\begin{array}{l}\text { Linear regression equations } \\
\qquad \mathrm{Y}=\mathrm{AX}+\mathrm{B}^{\mathrm{a}}\end{array}$ & Correlation coefficient $\left(\mathrm{r}^{2}\right)$ & LOD (pmol) & LOQ (pmol) \\
\hline Mannose & $Y=0.68 X+2.58$ & 0.9999 & 1.43 & 4.73 \\
\hline Galacturonic acid & $Y=1.79 X+24.57$ & 0.9997 & 0.54 & 1.78 \\
\hline Glucuronic acid & $Y=0.77 X+33.78$ & 0.9994 & 1.13 & 3.74 \\
\hline Rhamnose & $Y=0.47 X-6.55$ & 0.9995 & 2.06 & 6.82 \\
\hline Glucose + Galactose & $Y=1.65 X+25.89$ & 0.9998 & 0.37 & 1.22 \\
\hline Arabinose & $Y=1.64 X+31.01$ & 0.9997 & 0.33 & 1.10 \\
\hline Xylose & $Y=1.25 X+22.76$ & 0.9993 & 0.46 & 1.54 \\
\hline Fucose & $Y=0.72 X+11.05$ & 0.9997 & 0.75 & 2.49 \\
\hline
\end{tabular}

${ }^{\mathrm{a} X}$ : Injected amount (pmol), Y: Peak area.

TABLE-3

REPRODUCIBILITY, PRECISION AND ACCURACY OF EACH MONOSACCHARIDE DERIVATIVE

\begin{tabular}{|c|c|c|c|c|c|c|}
\hline \multirow{2}{*}{$\begin{array}{l}\text { NMP-monosaccharide } \\
\text { derivative }\end{array}$} & \multicolumn{2}{|c|}{ Reproduciblity $(\mathrm{RSD} \%)(\mathrm{n}=6)$} & \multicolumn{2}{|c|}{ Precision } & \multicolumn{2}{|c|}{ Accuracy $(\mathrm{n}=3)$} \\
\hline & Retention time & Peak area & Intra-day $(n=6)$ & Inter-day $(\mathrm{n}=3)$ & Recovery & RSD (\%) \\
\hline Mannose & 0.10 & 0.53 & 2.02 & 4.78 & 96.21 & 1.80 \\
\hline Galacturonic acid & 0.17 & 0.85 & 3.34 & 5.01 & 92.78 & 2.78 \\
\hline Glucuronic acid & 0.21 & 0.54 & 2.67 & 5.68 & 93.05 & 2.47 \\
\hline Rhamnose & 0.09 & 0.73 & 2.13 & 4.95 & 97.83 & 2.59 \\
\hline Glucose+Galactose & 0.06 & 0.43 & 1.84 & 3.97 & 99.45 & 1.56 \\
\hline Arabinose & 0.08 & 0.40 & 1.75 & 3.42 & 95.50 & 1.14 \\
\hline Xylose & 0.12 & 0.51 & 1.78 & 3.29 & 101.79 & 1.47 \\
\hline Fucose & 0.08 & 0.60 & 2.18 & 4.83 & 104.23 & 2.30 \\
\hline
\end{tabular}

of $3(\mathrm{~S} / \mathrm{N}=3)$, values of which varied from 0.33 to $2.06 \mathrm{pmol}$ (Table-2). Limits of quantification (LOQ) were defined to S/N $=10$, the values ranged from 1.10 to $6.82 \mathrm{pmol}$ (Table-2). Each monosaccharide standard with concentration of 500 pmol was injected $(n=6)$ to estimate the reproducibility of this HPLC-DAD method. Relative standard deviations (RSD \%) for the retention time validation were less than $0.21 \%$, whereas the RSD values for the peak area validation were less than $0.85 \%$. Method precision was investigated with S. involucrata sample, this process included hydrolyzation, derivatization and injection $(n=3)$. RSD values of inter- and intra-validation for the method precision ranged 1.75-3.34 and 3.29-5.68\%, respectively (Table-3). Additionally, recoveries varied from 92.78 to $104.23 \%$ and RSD values varied from 1.14 to $2.78 \%$ (Table-3).

Compositional analysis of polysaccharide from snow lotus: Monosaccharide composition of polysaccharides extracted from $S$. involucrata, S. laniceps and $S$. medusa were investigated (Fig. 5, Table-4). Total monosaccharide concentrations of $S$. involucrata, S. laniceps and $S$. medusa were $262.16,206.30,137.74 \mu \mathrm{g} \mathrm{mg}^{-1}$, respectively. In these three snow lotus, concentrations of galacturonic acid, rhamnose, glucose + galactose and arabinose were relatively high. Glucose + galactose presented the highest concentration (81.07 $\mu \mathrm{g} \mathrm{mg}^{-1}$ ) in $S$. involucrata. In S. laniceps, galacturonic acid was the most abundant one with concentration of $72.87 \mu \mathrm{g}$ $\mathrm{mg}^{-1}$. Highest glucose + galactose $\left(50.64 \mu \mathrm{g} \mathrm{mg}^{-1}\right)$ were found in $S$. medusa.

Assessment of antioxidant activities: After oxidation, ABTS was transferred to $\mathrm{ABTS}^{\circ+}$. When the corresponding antioxidant compound was added, colour of $\mathrm{ABTS}^{\bullet+}$ reagent would fade ${ }^{34}$. ABTS scavenging activities for the crude polysaccharides extracted from $S$. involucrata and S. laniceps

\begin{tabular}{lccc}
\hline \multicolumn{4}{c}{ TABLE-4 } \\
\multicolumn{4}{|c}{ CONTENTS OF THE RESPECTIVE MONOSACCHARIDES } \\
OF POLYSACCHARIDE FROM S. involucrata, \\
S. laniceps AND S. medusa $(\mu \mathrm{g} / \mathrm{mg})$ \\
\hline Monosaccharide & S. involucrata & S. laniceps & S. medusa \\
\hline Mannose & 6.66 & 12.94 & 5.65 \\
Galacturonic acid & 65.85 & 72.87 & 33.83 \\
Glucuronic acid & $\mathrm{nd}^{\mathrm{a}}$ & $\mathrm{nd}$ & $\mathrm{nd}$ \\
Rhamnose & 41.49 & 31.98 & 30.84 \\
Glucose+Galactose & 81.07 & 67.10 & 50.64 \\
Arabinose & 60.10 & 11.21 & 8.33 \\
Xylose & 4.85 & 5.64 & 5.90 \\
Fucrose & 2.14 & 4.57 & 2.55 \\
Total content & 262.16 & 206.30 & 137.74 \\
\hline${ }^{a}$ No detection or below the LOQ. & & \\
\hline
\end{tabular}

were similar. With different concentrations $\left(25-300 \mu \mathrm{g} \mathrm{mL}^{-1}\right)$, this activity increased with increasing amount of polysaccharide. Constant scavenging activities were achieved with concentrations $=400 \mu \mathrm{g} \mathrm{mL}^{-1}$. Compared with $S$. involucrata and $S$. laniceps, ABTS scavenging activity for crude polysaccharide extracted from $S$. medusa was relatively lower. With concentrations $25-500 \mu \mathrm{g} \mathrm{mL}^{-1}$, ABTS scavenging activity increased with increasing amount of polysaccharide (Fig. 6a).

The reducing power, which may serve as a significant reflection of the antioxidant activity, was determined by reduction of the $\mathrm{Fe}^{3+}$ to $\mathrm{Fe}^{2+}$. Increased absorbance of the reaction mixture indicates greater reducing power ${ }^{35}$. Fig. $6 \mathrm{~b}$ showed the comparison for the reducing power of polysaccharide extracted from $S$. involucrata, S. laniceps and $S$. medusa. All samples showed some degree of reducing power. The reducing power increased with increasing amount of polysaccharide. This ability of the crude polysaccharides from S. involucrate, S. laniceps was similar, which relatively higher than that of $S$. medusa. 

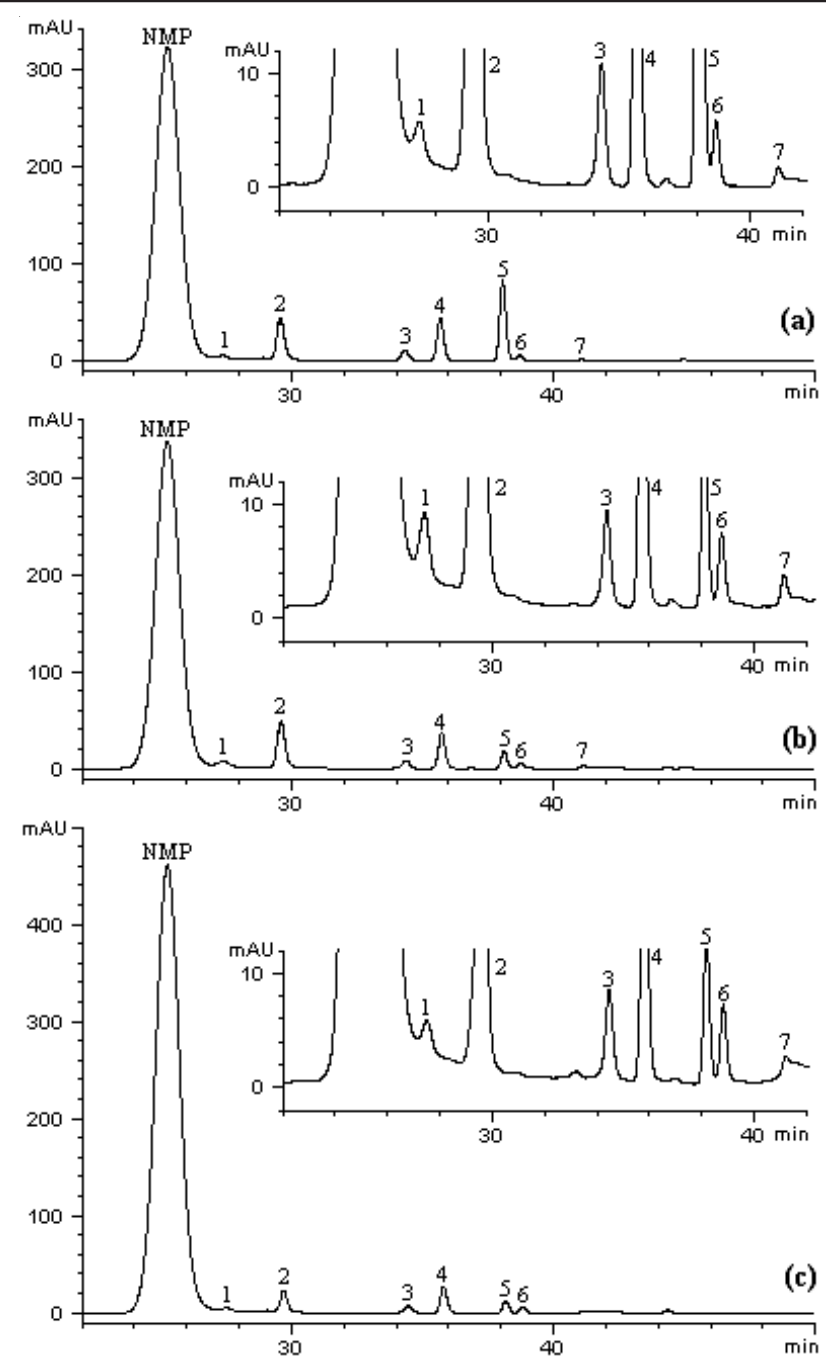

Fig. 5. Chromatograms for monosaccharide compositions of polysaccharides extracted from S. involucrata (a), S. laniceps (b) and $S$. medusa (c). Peaks: 1, mannose; 2, galacturonic acid; 3, rhamnose; 4 , glucose+ galactose; 5 , arabinose; 6 , xylose; 7 , fucose
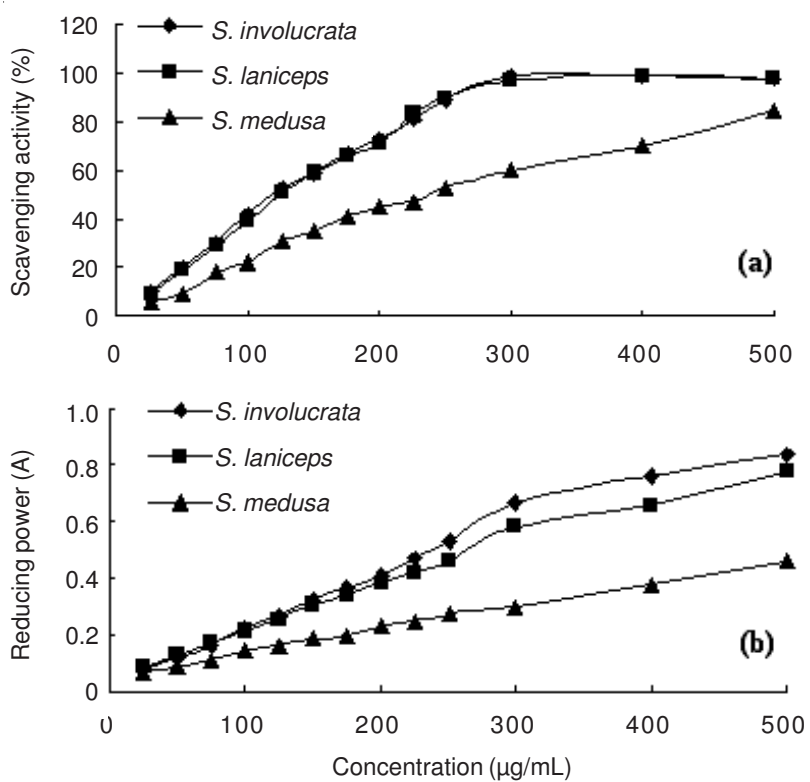

Fig. 6. Antioxidant activities of polysaccharides extracted from $S$. involucrata, $S$. laniceps and $S$. medusa: ABTS scavenging activities (a); the reducing power (b)

\section{Conclusion}

The HPLC-DAD-MS/MS method based on pre-column derivatization developed in this work proved to be reproducible (good sensitivity, linearity and precision) and accurate allowing the quantification of monosaccharide in polysaccharide from snow lotus. Galacturonic acid, rhamnose, glucose + galactose and arabinose were found to be the major components.

\section{ACKNOWLEDGEMENTS}

The authors gratefully acknowledged the financial support from Qujing Normal University.

\section{REFERENCES}

1. F. Chen, Y. Yang, D. Zhao, Y. Gui and Z. Guo, Chin. Bull. Bot., 16, 561 (1999).

2. J. Huang and D. Tan, J. Xinjiang Agric. Univ., 25, 8 (2002).

3. Q. Gan, Chinese Tradit. Herbal Drugs, 32, 371 (2001).

4. E. Buri, Q. Gema and D. Daoerji, J. Chin. Med. Mater, 27, 952 (2004).

5. T. Yi, H. Chen, Z. Zhao, Z. Jiang, S. Cai and T. Wang, Chromatographia, 69, 537 (2009).

6. X. He, G. Li and H. Chen, Northwest Pharmaceut. J., 5, 17 (1990).

7. T. Yi, Z. Zhao, Z. Yu and H. Chen, J. Ethnopharmacol., 128, 405 (2010).

8. S. Han, Carcin. Teratogen. Mut., 7, 80 (1995).

9. X. Xiao, L. Liu, R. Zheng, Z. Jia, Y. Li, M. Du and Z. Zhu, J. Lanzhou Univ., 22, 102 (1986).

10. X. Fang and W. Ye, J. Tianjin Med. Coll., 1, 41 (1983).

11. X. Lin and G. Wang, Acta Pharmacol. Sin., 21, 220 (1986).

12. C. Zhao, J. Geng and P. Wang, Med. J. National Defending Forces North China, 21, 1 (2009).

13. R. Zheng, G. Liu, G. Xing, Z. Jia, M. Du and L. Tan, Acta Pharmacol. Sin., 14, S47 (1993).

14. C. Fan and J. Yue, Bioorgan. Med. Chem., 11, 703 (2003).

15. H. Wang, J. Zuo and G. Qin, Fitoterapia, 81, 937 (2010).

16. M. Takasaki, T. Konoshima, K. Komatsu, H. Tokuda and H. Nishino, Cancer Lett., 158, 53 (2000).

17. C. Liu, Y. Deng, N. Du and L. Yang, J. Chinese Med. Mater, 31, 101 (2008).

18. T. Yi, H. Chen, Z. Zhao, Z. Jiang, S. Cai and T. Wang, Chromatographia, 70, 957 (2009).

19. P. Li, W. Sun, C. Luo, T. Shan, Y. Mou, S. Lu, Z. Mao and L. Zhou, Afr. J. Microbiol. Res., 6, 471 (2012).

20. Y. Honda-Okubo, F. Saade and N. Petrovsky, Vaccine, 30, 5373 (2012).

21. Y. Zuo, S. Ye, X. Wan, H. Fan and R. Ma, Food Sci., 22, 56 (2001).

22. X. Wu, G. Mao, Q. Fan, T. Zhao, J. Zhao, F. Li and L. Yang, Food Res. Int. (2012) in press.

23. Y. Ji, F. Dong, D. Ma, J. Miao, L. Jin, Z. Liu and L. Zhang, Molecules, 17, 7323 (2012).

24. X. Li, Y. Zhang, H. Kuang, F. Jin, D. Liu, M. Gao, Z. Liu and X. Xin, Int. J. Mol. Sci., 13, 1747 (2012).

25. T. Wang, X. Yang, D. Wang, Y. Jiao, Y. Wang and Y. Zhao, Carbohydr. Polym., 88, 754 (2012).

26. G. Karlsson, S. Winge and H. Sandberg, J. Chromatogr. A, 1092, 246 (2005).

27. S. Honda, E. Akao, S. Suzuki, M. Okuda, K. Kakehi and J. Nakamura, Anal. Chem., 180, 351 (1989).

28. J. You, X. Sheng, C. Ding, Z. Sun, Y. Suo, H. Wang and Y. Li, Anal. Chim. Acta, 609, 66 (2008).

29. R. Re, N. Pellegrini, A. Proteggente, A. Pannala, M. Yang and C. RiceEvans, Free Radical Bio. Med., 26, 1231 (1999).

30. J. Wang, Q. Zhang, Z. Zhang and Z. Li, Int. J. Biol. Macromol., 42, 127 (2008).

31. T. Ikegami and N. Tanaka, Curr. Opin. Chem. Biol., 8, 527 (2004).

32. M. Quirós, R. Gonzalez and P. Morales, Food Chem., 134, 1205 (2012).

33. M. van Gool, K. Toth, H. Schols, G. Szakacs and H. Gruppen, Bioresour. Technol., 114, 523 (2012).

34. X. Chen, D. Jiang, F. Chen and K. Yuan, Adv. Mater. Res., 343, 1098 (2012).

35. V. Ramesh, R. Hari, S. Pandian and G. Arumugam, J. Complem. Integr. Med., 8, 1 (2012). 